\title{
Observations and Perceptions on a Doctoral Research Seminar in Engineering and Logistics
}

\author{
Dave A. Louis (D) and Ingrid Rügge
}

\begin{abstract}
Logistics is a global challenge needing cooperation across disciplinary as well as cultural diversity. International, interdisciplinary education has the potential to provide meaningful experiences and cultural exchange for the individuals involved, including students, faculty, and university professionals and can have a positive impact on their lives and professionalism. We introduce the doctoral training program International Graduate School for Dynamics in Logistics (IGS) at the University of Bremen and explores a German-American educational partnership on the level of doctoral training. Utilizing scholarly personal narratives, the perceptions of two university professionals were garnered. From the narratives, they discussed the advantages and difficulties associated with cultural exchanges, the exposure to many cultures, and engaging with differing educational systems converging within one program. This qualitative study provides and glimpses into the complexity and intentional nuances that should be addressed when developing and operationalizing international, interdisciplinary education.
\end{abstract}

\section{Introduction}

This chapter focuses on an educational scientific examination of the phenomena that internationalization adds to the already challenging claim of interdisciplinarity. In the first part, the history, the concept, and thematic orientation of the interdisciplinary doctoral training group of the Bremen Research Cluster for Dynamics in Logistics of the University of Bremen is presented. Subsequently, an international cooperation with Texas Tech University in the United States and with mostly

D. A. Louis

College of Education, University of Houston, Houston, USA

e-mail: dalouis@central.uh.edu

I. Rügge $(\bowtie)$

International Graduate School for Dynamics in Logistics, University of Bremen, Bremen,

Germany

e-mail: ruegge@uni-bremen.de 
Ethiopian doctoral students is taken as an example, examined with a qualitative approach.

\section{Part 1: A Doctoral Training Program for Logistics}

The University of Bremen is a very young university that started with alternative study programs and exceptional curricular elements. The founding objectives have been interdisciplinarity, orientation to the practice, and social accountability in teaching and research from the beginning on. Over the years, these guiding principles have been expanded by gender equality, ecological accountability, and internationalization (Universität Bremen 2021). In 1995, several research groups from four different departments of the University of Bremen agreed to build a research cluster on logistics without making it a discipline in its own right. They identified logistics as a multidisciplinary and international area of research, transfer, and education.

Now, the established Bremen Research Cluster for Dynamics in Logistics (LogDynamics) is a cooperative network of research groups from five faculties of the University of Bremen: Production Engineering, Mathematics/Computer Science, Physics/Electrical Engineering, Business Studies/Economics, and Law. Associated partners are the BIBA-Bremer Institut für Produktion und Logistik GmbH, the Institute of Shipping Economics and Logistics (ISL), and the Jacobs University Bremen $\mathrm{gGmbH}$. The fields of activity range from fundamental and applied research to transferring results into practice.

When starting the implementation of the research cluster, the idea arose to support young researchers in this interdisciplinary field in a structured manner. At that time, there was already structured doctoral education in Germany, but very rare in the engineering sciences. With a Master (or the old German degree "Diplom") German doctoral students usually are not treated as students anymore. They are doctoral candidates: young, independent researchers, working for their living in sciences and self-responsible for any further education. Doctorates of research assistants were common practice, mostly in German and with a low proportion of foreigners.

As LogDynamics recognized the need for systematization of doctoral training and its internationalization, especially in logistics, it set up the International Graduate School for Dynamics in Logistics (IGS) in 2014, doctoral students were recruited. Funding for the IGS began with an initial funding by the state of Bremen, which provided funds for infrastructure, structural supervision, and scholarships. In the meantime, the doctoral scholarships come from the DAAD, from the home countries of the international scientists, or from the Erasmus funding schemes of the EU. The IGS has been a partner in three Erasmus Mundus mobility projects with Asia (cLINK, FUSION, and gLINK) from 2012 to 2018. Furthermore, it hosted twice in a row a PhD SummerCamp for Ethiopian doctoral students from Texas Tech University, USA (TTU Summer Camp 2018). Since 2021, the IGS is one of two 
European partners in the Erasmus+ Capacity Building Project SSAPI with Asia. Structural support of the IGS still continues to be funded locally.

The first structuring of the new doctoral training program was taken from already successfully implemented ones in the social sciences, humanities, and marine sciences at the University of Bremen. The IGS adapted it to the conditions in engineering and to the interdisciplinary and international aims of the research cluster. The resulting support system was recognized by all disciplines involved in $\log$ Dynamics. The curriculum of the IGS is tested, evaluated, and continuously improved to this day (Rügge and Himstedt 2015; Rügge and Scholz-Reiter 2011; Scholz-Reiter and Rügge 2011).

The incoming scholarship holders pursuing their doctoral research at the IGS benefit from disciplinary supervision, scientific mentoring as well as organizational and social support. Beside the individual doctorate projects, the curriculum covers subject-specific courses, interdisciplinary research colloquiums, dialogue forums with the industry, excursions, international conferences, and individual coaching. The IGS integrates visiting professors into the supervision of the theses and external experts for specific training in the field of personnel development. The working language is English. The objective is to foster excellence in higher education and research by providing an optimal environment in the field of logistics research on different levels.

The IGS meets the challenge of globalization in logistics through doctoral research in the same areas LogDynamics is focusing on. The individual research is centered on four topic areas:

- Business models, decision processes and economic analyses of dynamics in logistics.

- Holistic interdisciplinary methods for modeling, analysis, and simulation of dynamics in logistics.

- Adaptive and dynamic control methods in logistics.

- Synchronization of material, information, decision, and financial flows.

The implemented supporting measures are courses, training, and coaching, most of them related to improving so-called soft skills, e.g., to gain more awareness on the impact of cultural differences and languages in scientific as well as social cooperation (Zhang et al. 2015). The IGS is combining scientific content with personnel and personality development in all offered measures as a "hidden agenda" (Rügge and Klempien-Hinrichs 2013).

In 15 years, 100 courses or organizational course units were conducted, in which nearly 300 scientists participated; that equals 1550 participations in total. The majority of the participants are doctoral candidates, i.e., scholarship holders of the IGS or research assistants of LogDynamics. However, international guests from several mobility programs, not all of them conducting a $\mathrm{PhD}$, have also participated in the courses of the IGS.

At this current juncture, 76 young researchers from twenty-four countries started their doctorate with a scholarship at the University of Bremen within the framework provided by the IGS. Fifty-three of them have been awarded a doctoral degree 
(IGS 2021). They are professionally supervised by LogDynamics professors in one discipline and also submit their dissertation in that discipline. The majority of the doctoral theses have been submitted to the three Engineering faculties Production Engineering (21), Electrical Engineering/Physics (12), and Mathematics/Computer Sciences (8) of LogDynamics; ten to Business Administration/Economics. As diverse and individual as doctoral topics are, they have always had a strong relation to logistical problems. Among others, a significant scientific contribution was made to autonomous logistics as well as to the modeling and optimization of different kinds of supply chains, to the modeling of uncertainties and trust, to AI-based decision support, to protocols of mobile communication for Industry 4.0 applications, to sensors and sensor networks for food transports.

Through the measures of the IGS, however, there is a continuous moderated interdisciplinarity during the average 4-year doctoral phase. In addition, the provided customized continuing education courses are accessible to all LogDynamics scientists, regardless of their contracts. Researchers pursuing their doctorates within a traditional assistance doctorate as well as postdocs, professors, and guest researchers are addressed by the offered courses. The orientation and composition of the courses is not left to chance but is also guided with regard to an interdisciplinary and international mix.

Sixty-seven of the 100 courses offered by the IGS have been evaluated by the participants. Quantitative evaluations as well as qualitative feedback were requested using a standardized questionnaire. The aim of each evaluation is to improve the IGS offering, so there were also queries. The evaluation was therefore not anonymous. This had as a positive effect an above-average return of answers as well as detailed answers and discussions of the organizer on HOW to adapt the course to the current needs with participants and lecturers. On average, between 11 and 23 people participated in a course in 12 years under consideration. The proportion of IGS doctoral scholarship holders varied from $24 \%$ to $56 \%$ and averaged $37.5 \%$ overall. The proportion of women in this period varied between $31 \%$ and $54 \%$, for an average of $43 \%$. On a scale of 1 (excellent) to 6 (poor), $88 \%$ of the evaluated courses received an average rating better than 2.5 , meaning that only eight courses received a lower rating. 41 were rated in the upper range of 1.

All offers of the IGS are not general, they always undergo a specific adaptation that takes into account the realities of logistics, i.e., the related disciplines, the international cooperation, and the composition of the participants. For this purpose, the lecturers are also sensitized to these specifics in advance and during the implementation of the courses, and the specifics are made explicit. The qualitative study introduced in the second part of this paper emerged from this sensitization.

\section{Part 2: Study on International, Interdisciplinary Education}

International education, in its many forms and fashions, provides meaningful experiences and leaves lifelong impressions to students who engage in it. Concurrently, educators who are engaged in this endeavor also find much meaning 
in developing programs and interacting with the students. This cooperative paper explores the experiences of two educators involved in a doctoral summer program on professional writing as a component of an international education experience of engineers within a partnership between the United States, Ethiopia, and Germany. Unique to this partnership were (a) the interdisciplinary nature of the endeavor, (b) doctoral candidates from different disciplines from Ethiopia, (c) professors from the United States, (d) an international, interdisciplinary doctoral training group housed at a university in Germany, and (e) the summer course that coalesced the international experience. This paper will explore the perceptions of the professor from the College of Education at Texas Tech University (TTU) in the United States and the managing director of the International Graduate School for Dynamics in Logistics (IGS) in Germany.

\subsection{International Educational Experiences}

Gelpi (1985) espouses intercultural activities in higher education inevitably furnishes students and teachers with greater levels of confidence. He posits that intercultural activities involving higher education institutions that focus on global collaboration are beneficial to the students, the institutions, and the environments they influence. With these similar notions as Gelpi as the undergirding notions, the College of Engineering and the College of Education at TTU embarked upon collaborating with Jimma University in Ethiopia to develop graduate degrees in engineering and teach many of the courses therein. The impetus was not only to create international collaborations but to enhance the educational landscape of Ethiopia by the creation of science teachers and university professors through graduates of the program. One significant component of the program was to provide the Ethiopian students with an international experience outside of their home country. It is through this component that the IGS and the BIBA became an important and indispensable element. Between July 2017 and July 2018, 18 Ethiopian doctoral students traveled to Bremen, Germany, and engaged in academic international experience for three months at the "TTU PhD SummerCamp." BIBA served as administrative host of the three months of international experiences of Ethiopian doctoral candidates and their American professors; the IGS managed all organizational issues and developed the program in Germany.

Another crucial component of the program was to develop the students' skills in professional and publication writing. These two components gave rise to the interdisciplinary writing intensive course within the TTU PhD SummerCamp. This "Research Seminar" with the title "Proposal Writing: Professional Presentations and Publications" was implemented for two consecutive years. The faculty member from the College of Education at TTU designed it; and the experiences and observations of the facilitators of the program encapsulated and exemplified intercultural cooperation among different countries. Some parts of the curriculum of the course have been by email before and after the presence phase. In the first year, the 
scientific managing director of the IGS joined some classes of the research seminar. During and after the course, both educators discussed their experiences and started comparing the American and German system of supporting doctoral candidates. That was the moment to start the research and cooperation for this chapter. In the second year, there were less Ethiopian doctoral candidates left for an international experience as well as for participating in the Research Seminar. Therefore, the educators considered opening the course to doctoral candidates from LogDynamics. An adaption of the Research Seminar was necessary to meet both needs: the needs of the Ethiopian doctoral candidates of the American system and the needs of those who are going to finish their doctorates in the German system.

\subsection{TTU PhD SummerCamp Research Seminar}

The Research Seminar course was developed to engage students in activities related to writing research proposals, presenting their research, and preparing their research for publication at the doctoral level, which included dissertation proposal preparation. Although the development of specific presentation and writing skills stood at the core of the course, the faculty member of TTU lectured on issues surrounding proposal structure, meaning, and purpose of the proposal, understanding a professional and scientific audience, preparing research for publication, and preparing research for professional presentations. Imbedded in the course were activities for the students to critically think about their role as a researcher and develop strategies to enhance their presentation, mentoring of others, and pedagogy. Over the 2-year span, the course was amended from a one-week course to a 2-week course. The first year only Ethiopian students were enrolled; and the second-year doctoral candidates from both Jimma University and the University of Bremen were enrolled. The observations by the faculty developer and the IGS managing director serve as the primary data source for this piece.

\section{Qualitative Research Methods}

Through scholarly personal narratives (SPN) (Nash 2004), the perceptions of the two university professionals associated with a German-USA educational partnership were explored relating to their experiences with the development and execution of an academic program for Ethiopian and Bremen doctoral students. Gorichanaz (2017) posited, "the collaborative, phenomenological approach to self-study [can] to allow for deep personal reflection while also stimulating open conversation among researchers and educators" (p. 4). An integral aspect of the design was plural positionality (Louis et al. 2017) since the authors are the above-mentioned university professionals and served as both (a) the participants, key informants, who articulated their experiences, and (b) researchers, who analyzed the meaning 
of their experiences. The data from the written narratives served as the primary data. Through the data analysis process, meanings of the experiences are developed and explicated (Nash 2004; Patton 2014; Lincoln and Guba 1985).

The research questions (RQs) that guided this narrative inquiry were: What are the perceptions of the two interacting educators about:

- RQ1: the inception of the international partnership and the program?

- RQ2: benefits and challenges of the international partnership and the program?

- RQ3: the vision and aspiration of the international partnership and the program?

- RQ4: the experiences of students who participated in the international partnership and the program?

- RQ5: the multidimensional features of the international partnership and the program?

\subsection{Procedure and Analysis}

An instrument consisting of six items/prompts was developed (Appendix A) for the researchers, who were the university professionals, to reflect and compose their narratives on their perceptions two university professionals associated with a German-USA educational partnership. The prompts were framed from the RQs focused on their experiences and observations as educators involved in a multidisciplinary/multidimensional international collaboration between two universities. Before the instrument was distributed to the university professionals, it was vetted by the primary researcher to an independent qualitative researcher to make certain that the prompts were accurate and clearly addressed the fundamental nature of the study. The university professionals were given four weeks to reflect on the prompts, make notes and write sections, edit and re-edit, and construct their narrative with no limits on expression or articulation.

The narratives were distributed to each researcher, who were the university professionals involved in the TTU PhD SummerCamp, for individualized independent analysis for open coding. Subsequently, they met via Zoom to discuss their findings, disaggregate the data, delve further into the meanings of the narratives, and clarify the expressions. It provided opportunities for member-checking whereby clarity of meaning and ensuring the accuracy of the information was the central activity. The process of axial coding in the data analysis linked the common connections between the participants' responses showing shared observations and mutual perceptions about the events, individuals, experiences within the program (Saldaña 2015). From this exercise, themes emerged from the narratives. Additionally, the study ascribed to Lincoln and Guba's (1985) concept of trustworthiness. The self-analysis design and analysis discussions provided opportunities to further explain and clarify their meanings and experiences. This member-checking and reevaluation enabled the researchers to extricate very detailed and pertinent meanings of experiences with relation to their experiences and perceptions. 


\subsection{Positionality}

Positionality is vital when communicating individuals' life experiences, insights, observations, and expressions of realities (Bourke 2014). Holmes (2020) stated, "The term positionality both describes an individual's world view and the position they adopt about a research task and its social and political context" (p. 1). Hence, being cognizant of the researcher's context is key to understanding their lens when engaging in the process, data, analysis, and theme development. And for SPN their roles as key informants call specifically for a comprehension of their backgrounds.

Dave is a tenured associate professor in higher education at a large public research university in the United States. He has over twenty years of experience in American higher education, holding positions ranging from director of student success center to executive director of a large academic program to tenure-track faculty. He has spent 8 years as a faculty member in the College of Education at Texas Tech University and is currently embarking on his initial term as a faculty member at the University of Houston. He is originally from Trinidad in the Caribbean but has lived the majority of his life in the United States. He identifies as an Afro-Indo-Trinidadian.

Ingrid is a managing director at a young, medium-sized public research university in Germany. She worked in different positions: Firstly, eight years in technology transfer at an interdisciplinary Research Center at the University of Bremen. For 14 years, she has been working as coordinator of an international doctoral training program of an interdisciplinary research cluster. She guided more than 50 doctoral candidates of logistics from 24 different countries successfully through their doctorate procedures in five different disciplines at the University of Bremen.

\section{Findings}

By now, two major themes emerged from the analysis of the narratives: (1) Bunter Blumenstrauß and (2) Academic Approach Convergence. The themes directly address the two university professionals' perspectives with a German-USA educational partnership. It reflected their insights, experiences, observations, interactions, and involvement with the TTU PhD SummerCamp. Although qualitative work is not generalizable, the findings can indeed shed light, provide perspective, and create greater awareness when developing cross-national and international educational programs.

\subsection{Theme 1: Bunter Blumenstrauß}

"Bunter Blumenstrauß" roughly translates into a "colorful bunch of flowers." Throughout the narratives, the wondrousness of the multiplicity of people, mixture 
of cultures, and differing educational systems converging in one place were expressed. The TTU PhD SummerCamp possessed one academic goal, but concurrently embraced and utilized the differences within the cultures and systems to benefit the students' learning outcomes. Thus, it was a symphony and cacophony of cultures wrapped under the banner of education. The beauty of the program, as well as some of the struggles within the program, was rooted in the diversity of the German, American, Ethiopian, and other cultures engaged in a common academic journey.

Dave articulated that the multicultural components of the program were what enriched the program and was one of the central aspects of the design. He stated,

part of the core aspiration was the exchange of ideas and culture internationally. The program is one meant to expose all the students and faculty involved to different cultures, ways of thinking, and different educational systems with the hope that the African students will ultimately benefit from both the academic program and cultural exposure.

Within the design, Ingrid indicated that the Ethiopian students in particular had to adjust to German culture because they immersed for an extended period of time. Although the program was a magnificent opportunity for the students. She stated,

Most of the Ethiopian doctoral candidates had never been abroad nor in a Western country before the TTU PhD SummerCamp in Germany. Their stay was limited to three months; thus, they had to adapt to daily life very quickly. The project brought three cultures (and languages) together...

However, what is important to note was her belief that three months may not have been sufficient for students to adapt to the culture of both the host country and the academic and social expectations. Ingrid indicated,

Gaining international experience takes time! Three months is not sufficient to break someone out of her/his comfort zone, particularly not when [individuals start] in a homogeneous [cultural] group. It takes much longer to generate (automatic) awareness for intercultural, international, interdisciplinary and diverse encounters.

Dave, however, did have an instance in which he engaged with an Ethiopian student outside of the classroom and observed the importance of the international collaboration. Dave shared,

I believe that the students developed through both the academic courses and the cultural exchange. I rode the train one evening with one of the students and the conversation we had about what he learned from being Germany was amazing. Plus, he seemed comfortable navigating life in Bremen. He was comfortable on the train and in the city and expressed his enjoyment in living in an apartment in the city.

Through both narratives, it was clear that the TTU PhD SummerCamp offered a great benefit to the students involved. However, within any bunch of flowers thorns/Dornen exist. With the amalgam of cultures, there were instances when there were some complications with respect to academic, societal, and cultural expectations. Ingrid shared,

[It] was a challenge for the Ethiopians even if they received tremendous support from the hosting institution. They stuck together most of the time and didn't make any friends with 
Germans, neither the first group nor the three people of the second year. Integration was impossible.

There were instances of language barriers, academic expectation parries, and societal expectations barriers. Dave explained,

The two biggest challenges were language and academic expectations. Most of the class instruction was conducted in English. The instructor's native tongue was English (British) and operates within an educational system that is also English (USA). The two main coordinators of the program both spoke languages other than English (German and Kenyan), the Ethiopian students spoke their native Ethiopian language, the German students spoke German. Thus, there were times when explanation of 'technical terms' was necessary and unexpected.

Although in the first year, the primary languages were rooted in the German, American, and Ethiopian cultures, in the second year with the inclusion of the Bremen doctoral students, there were people who were Chinese and Indonesian. So, beyond the confluence of German, American, and Ethiopian academic structures was the additional layer of multiple native languages of the students and the exposure to multiple academic higher education systems. Overall, the Research Seminar provided a platform and landscape for multiple cultures to be engaged in an academic program for doctoral students and include three countries in the development. Although the cultural exchange was extremely beneficial and was one of the most admirable aspects of the TTU PhD SummerCamp, it did have elements that resulted in some difficulty.

\subsection{Theme 2: Academic Approach Convergence}

It was clear that multiple academic systems would be converging during the development and operationalization of the TTU PhD SummerCamp. The curriculum and degree outline for the Ethiopian doctoral students at Jimma University were American and crafted as such. The students matriculated undergraduate and master's degrees in Ethiopia under the auspices and rubric outlined by the Ministry of Education in Ethiopia. However, for organizational reasons, the TTU PhD SummerCamp took place at the University of Bremen in Germany. In the second year, with the addition of the students pursuing doctoral degrees in a German system, the differences in academic approaches became more apparent. Thus, there was an inherent convergence of academic paradigms that was expected. But this challenge also allowed both university professionals to examine and learn about other educational structures.

Ingrid aptly expressed that both she as a professional and the students would be able to garner a glimpse into other educational systems. She shared,

There was the chance for a few doctoral candidates of the German system to benefit from a regular course of the US system for doctoral candidates... [and] the managing director of the IGS had the opportunity to look into the US education system for doctoral candidates. 


\section{Concurrently, Dave was able to realize through both cycles of the program that,}

The structure of the thesis or dissertation and academic publishing was foreign or strange to many of the participants. Understanding the rationale and form of writing was complicated. Many students viewed it as discipline specific differences but as I examine it further it was more an educational system expectation that may not be common in Ethiopian or German systems. Thus, the differences within the system were highlighted in the academic writing.

Additional to the differing academic structures was the overlap of closely related yet independent disciplines represented in the classroom. Ingrid noticed,

Multi-disciplinarity was not intended specifically in the program. It was a coincidence that already the first, culturally homogeneous group of participants of the Research Seminar brought doctoral topics from different disciplines. As a result, each of them also had a different scientific background. For the second course, it was clear that there would be disciplinary diversity as well as participants from several different nationalities.

Thus, emanating from the analysis of the observations was the idea that although international partnerships may have overt comprehension of cultural confluence, they could be more intentional at the outset to explore the academic approach differences between educational systems and models.

Both Dave and Ingrid observed and commented on the differing research paradigms particularly between the American and German systems. The German doctoral approach in Engineering was one that starts the research path mostly with "field, project and experience"-based questions of the real world, whereas the American model seemed steeped more in the theory surrounding research and literature reviews before thoroughly noticing the real world's evidence and starting engaging in fieldwork. Both professionals agreed that the expected and delivered outcomes (theses) were the same but the approaches in educating students are different. And this difference became evident in the writing process, which was at the central focus of the Research Seminar. Ingrid stated,

In Germany, there is no tradition to train how to write down one's research idea. In the German research tradition in engineering, writing about one's research holds second place behind 'carrying out' the research proper. In the US system (and therefore valid for the Ethiopian doctoral candidates of this Research Seminar) it seems that students first need to write their ideas down in a structured form and then the ideas will be evaluated whether they are worth being followed through. Basically, both groups need the same course contents about writing. The mindset in which these contents are approached makes it easier or harder on students to profit from the course. In the second year group, the Ethiopians absorbed more from Dave than the student from Bremen. The latter reflected Dave's teachings and ended up somewhat opposed since the Research Seminar seemed to be 'just about pretty words'.

\section{Dave explained his observations,}

The structure of the thesis or dissertation and academic publishing was foreign or strange to many of the participants, especially those from the German system. Understanding the rationale and form of writing was complicated. Many students viewed it as discipline specific differences but as I examine it further it was more an educational system expectation that may not be common in Ethiopian or German systems. Thus, the differences within the system were highlighted in the academic writing ... One way I addressed this was through my pedagogy. My delivery always engaged the students in manners in which specific 
disciplines would express their research. Students had to find published articles to also understand the writing style and flow of their area. Overall, it was not difficult to merge disciplines. My experience is to teach writing across disciplines, so it was not difficult for me, but students sometimes had difficulty making sense of certain aspects of the writing. And some did not see the connection between their work and having to express it to an unknown audience.

The Research Seminar for the TTU PhD SummerCamp in numerous ways challenged the thinking and pushed the paradigmatic barriers of both the students and educators. It caused some level of dissonance where individuals had to wrangle and discover the academic space between "possessing knowledge" and "expression of knowledge." Students had to step outside of their comfort zones when addressing how to express their research, and the university professionals had to find ways to foster meaning-making between "knowledge" and "academic articulation." This becomes even more complex when culture, language, and multidisciplinarity are part of the classroom ecology.

\section{Conclusion}

According to Quacquarelli Symonds [QS] (2019), international partnerships "have contributed endlessly to academic and scientific progress" (para. 10) and benefit the students and the institutions on several levels. Furthermore, these partnerships cultivate research opportunities, cultural awareness, international experiences, curriculum development, and degrees formed in collaboration with partner institutions (QS, 2019). The partnership between TTU and the University of Bremen with the TTU PhD SummerCamp provided all of those elements to Ethiopian doctoral students from Jimma University and German, Chinese, and Indonesian doctoral researchers at the University of Bremen. This narrative study outlines two components that the program provided and sheds light on the complex nature of such a partnership. The program provided both the students and the educators with the opportunity to expand their horizons both culturally and academically. The IGS organized living accommodation, cultural and professional tours, and social opportunities for the Ethiopian students to interact with members of the German university and engineering community. Differences in cultural expectations and contrasting cultural mores, norms, and folkways were some of the obstacles that individuals in the program observed. Language barriers, contrasting academic structures, and multidisciplinarity posed challenges particularly in terms of comprehension of what was needed to be fully successful in the Research Seminar. However, despite these drawbacks, the researchers, who were involved in both coordinating the program and teaching the course, assert that the program overall was beneficial to the students and the German and American universities. The authors posit that engaging in long-term cultural discussion about academic expectations should be a key component in the development and strategic planning of any international partnership. Fostering a greater understanding of the academic structures of the 
countries' university systems, the differences in academic approaches with respect to attaining degrees, and delving into the philosophical underpinnings of the partner universities' curriculum are crucial to consider in program development. Additionally, cultural competency should be a component of both students' and professionals' preparation for the program. For the TTU PhD SummerCamp, the professor for the United States spoke English fluently as his native language and possessed a marginal grasp of German. The German coordinator spoke German fluently as her native language and possessed a good grasp of English. Neither spoke any Ethiopian language. The command of English of the Ethiopian students was medium, none of them spoke any German language. Not feeling comfortable with a (foreign) language may be a barrier. The unexpressed assumptions and implicit rules hidden in the foreign system cause a much higher barrier. Therefore, universities who are considering developing international partnerships should seriously consider providing educational professional development of their faculty and staff with respect to getting aware of the culture of their partner institutions. Furthermore, educators of international students (on all levels of education) should receive the opportunity to train their perception of culturally founded differences and to make it explicit. Training and experiences are needed to develop these abilities before one can share or teach them.

\section{Outlook}

This example of the German-USA international partnership between TTU and the University of Bremen exemplifies the importance of intentional program design, the crucial nature of identifying the distinctions between university systems, and the acknowledgment of the continued benefit of opportunities for cultural exchange across, between, and amongst nations of the world. The cooperation on educational research of both of the educators involved in the study will be extended by a Fulbright-funded research stay of Dave Louis at the IGS in 2022. Furthermore, the IGS is sharing its experiences with the Asian partners of the Erasmus+ Capacity Building project SSAPI as well as with the international partners gained by the alumni of the IGS.

The interdisciplinary research focus of the next incoming doctoral candidates of the IGS will be closely related to those of LogDynamics. The trend toward individualization has taken hold of logistics. The rapid growth of e-commerce in the current Corona pandemic has given this trend an additional boost. Increased mobility and more packaging material are the results. On the other hand, the effects of climate change are now evident, requiring logistics to reduce environmental toxins and improve the robustness of logistics supply chains. This raises new research questions whose treatment is of international interest and can only be answered meaningfully in interdisciplinary cooperation. This applies in a similar way to production, civil, or construction engineering. Therefore, the examination of 
factors of successful international interdisciplinary education and identifying best practices will be continued and intensified.

Acknowledgments The TTU PhD SummerCamp was part of the TTU project "Postgraduate Programs for Civil Engineering and Construction Technology." It has been funded by The Ministry of Education of the Federal Democratic Republic of Ethiopia (through the British Council and with the financial support of the German Development Cooperation (GIZ)). Many thanks go to Dr. Renate Klempien-Hinrichs who helped Ingrid with several methods to put her thoughts into a precise structure and English sentences.

\section{A.1 Narrative Prompts}

\section{A.1.1 Narrative Prompt 1: Inception of the Partnership and the Program}

As you think about the creation of the international partnership what were the main motivating factors in your mind for the program to be created? Why was it important for this partnership and program to be created? What was the core purpose of the program to be established? Who was it supposed to benefit? After it was completed (both year 1 and year 2) were the goals of the program achieved? Why would you say they were or were not achieved? What were the most positive aspects of working with interactional partners? What were the most negative aspects of working with the international partners?

\section{A.1.2 Narrative Prompt 2: Program Vision and Aspiration}

What did you envision this program to be for your university/unit? What did you aspire this program to be for the students involved? What were the outcomes you had hoped for during its creation (for the students and the administrators involved)? What did the partners express they wanted from the program? Was what the administrators wanted different from what you wanted as an educator?

\section{A.1.3 Narrative Prompt 3: Challenges}

Were there challenges in the creation of the program? Describe any challenges you had working with a university from another country? How were these challenges overcome? Describe any challenges you had with students? 


\section{A.1.4 Narrative Prompt 4: Student Experiences}

How would you describe the overall experience of the students who participated in the program? Describe what you believe were some of the most positive experiences that the students had while participating in the program? Describe what you believe were some of the most positive benefits that the students acquired while participating in the program? Describe what you believe were some of the most negative experiences that the students had while participating in the program?

\section{A.1.5 Narrative Prompt 5: Multidimensional}

How did the idea of multidimensional/multidisciplinary education influence the development of the program? Were there challenges with the merging of the four disciplines? How did you overcome or address the challenges associated with being multidimensional? What did you have to explain or translate for your international partner about the differences in educational expectations between the two countries? Were there language barriers about educational terms? Describe these barriers? Share how the barriers were overcome?

\section{A.1.6 Narrative Prompt 6: Conclusion}

Now that the program is completed, where are the most beneficial aspects of the program? What was the most positive aspect of the program? What elements of the program would you like to see replicated in other programs? What have you learned, as an administrator, from being involved in this program? What have you learned, as an educator, from being involved in this program?

\section{References}

Bourke, B.: Positionality: Reflecting on the research process. Qual. Rep. 19(18), 1-9 (2014)

Gelpi, E.: Lifelong Education and International Relations. Croom Helm, London (1985)

Gorichanaz, T.: Auto-hermeneutics: A phenomenological approach to information experience. Libr. Inf. Sci. Res. 39(1), 1-7 (2017). https://doi.org/10.1016/j.lisr.2017.01.001

Holmes, A.G.D.: Researcher positionality - A consideration of its influence and place in qualitative research - A new researcher guide. Int. J. Educ. 8(4), 1-10 (2020). https://doi.org/10.34293/ education.v8i4.3232

IGS: Alumni of the IGS (2021). Retrieved from http://www.logistics-gs.uni-bremen.de/ alumni.html? \&L=1 (last visit July 25, 2021)

Lincoln, Y.S., Guba, E.: Naturalistic inquiry. Sage, Newbury Park, CA (1985) 
Louis, D.A., Thompson, K.V., Smith, P., Williams, H.M.A., Watson, J.: Afro-Caribbean immigrant faculty experiences in the American Academy: Voices of an invisible black population. Urban Rev. 49(4), 668-691 (2017). https://doi.org/10.1007/s11256-017-0414-0

Nash, R.: Liberating Scholarly Writing: The Power of Personal Narrative. New York (2004)

Patton, M.Q.: Qualitative Research \& Evaluation Methods. Sage, Thousand Oaks, CA (2014)

QS [Quacquarelli Symonds]. Why are International Collaborations so Important For Universities? (2019). Retrieved from https://www.qs.com/why-are-international-collaborations-soimportant-for-universities/

Rügge, I.; Himstedt, A.: Multidimensionale Diversität in der Logistikausbildung. In: Industrie 4.0 Management, 2/2015, GITO Verlag, Berlin, pp. 61-65 (2015)

Rügge, I.; Klempien-Hinrichs, R.: Coping with Multi-Dimensional Diversity in Logistics Education in Proceedings of 6th IFAC International Conference on Management and Control of Production and Logistics (MCPL), Fortaleza, Brazil, September 11-13, 2013, pages 456-462, (2013) IFAC-PapersOnline, DOI: https://doi.org/10.3182/20130911-3-BR-3021.00101

Rügge, I., Scholz-Reiter, B.: Internationalization of the Doctoral Training Program for the German Degree “Dr.-Ing.", In: Proceedings of SKIMA 2011, Benevento, Italy, IEEE (2011). https:// doi.org/10.1109/SKIMA.2011.6089998

Saldaña, J.: The Coding Manual for Qualitative Researchers. Sage, Thousand Oaks, CA (2015)

Scholz-Reiter, B.; Rügge, I.: Promovieren im Forschungsverbund LogDynamics: international + interdisziplinär $=$ vernetzt. In: Hippler, Horst (Hrsg.): Ingenieurpromotion - Stärken und Qualitätssicherung. Heidelberg u.a.: Springer, S.115-124 (2011)

TTU SummerCamp. TTU PhD SummerCamp in Bremen (2018). Retrieved from http:// www.logistics-gs.uni-bremen.de/467.html? \&L=1 (last visit July 25, 2021)

Universität Bremen: Mission Statement (2021). Retrieved from. https://www.uni-bremen.de/en/ university/profile/mission-statement (last visit July 25, 2021)

Zhang, H., El-Berishy, N., Zastrau, D., Marwat, S.N.K., Tan, Y., Palafox, J., Rügge, I.: Interdisciplinary perspectives on knowledge management in logistics. In: Dethloff, J., Haasis, H.-D., Kopfer, H., Kotzab, H., Schönberger, J. (Eds.): Logistics Management: Products, Actors, Technology - Proceedings of the German Academic Association for Business Research, Bremen, 2013 (Lecture Notes in Logistics). Springer, pp 491-504 (2015)

Open Access This chapter is licensed under the terms of the Creative Commons Attribution 4.0 International License (http://creativecommons.org/licenses/by/4.0/), which permits use, sharing, adaptation, distribution and reproduction in any medium or format, as long as you give appropriate credit to the original author(s) and the source, provide a link to the Creative Commons licence and indicate if changes were made.

The images or other third party material in this chapter are included in the chapter's Creative Commons licence, unless indicated otherwise in a credit line to the material. If material is not included in the chapter's Creative Commons licence and your intended use is not permitted by statutory regulation or exceeds the permitted use, you will need to obtain permission directly from the copyright holder.

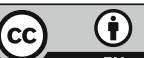

